Article

\title{
Enantioselective Transamination in Continuous Flow Mode with Transaminase Immobilized in a Macrocellular Silica Monolith
}

\author{
Ludivine van den Biggelaar ${ }^{1}$, Patrice Soumillion ${ }^{2}$ and Damien P. Debecker ${ }^{1, *}$ \\ 1 Institute of Condensed Matter and Nanosciences, Université catholique de Louvain, Place Louis Pasteur, 1, \\ Box L4.01.09, 1348 Louvain-la-Neuve, Belgium; ludivine.vandenbiggelaar@uclouvain.be \\ 2 Institute of Life Sciences, Université catholique de Louvain, Place Croix du Sud 4-5, 1348 Louvain-la-Neuve, \\ Belgium; patrice.soumillion@uclouvain.be \\ * Correspondence: damien.debecker@uclouvain.be; Tel.: +32-10-47-36-48
}

Academic Editor: Keith Hohn

Received: 10 January 2017; Accepted: 7 February 2017; Published: 10 February 2017

\begin{abstract}
Transaminases have been immobilized on macrocellular silica monoliths and used as heterogeneous biocatalysts in a continuous flow mode enantioselective transamination reaction. The support was prepared by a sol-gel method based on emulsion templating. The enzyme was immobilized on the structured silica monoliths both by adsorption, and by covalent grafting using amino-functionalized silica monoliths and glutaraldehyde as a coupling agent. A simple reactor set-up based on the use of a heat-shrinkable Teflon tube is presented and successfully used for the continuous flow kinetic resolution of a chiral amine, 4-bromo- $\alpha$-methylbenzylamine. The porous structure of the supports ensures effective mass transfer and the reactor works in the plug flow regime without preferential flow paths. When immobilized in the monolith and used in the flow reactor, transaminases retain their activity and their enantioselectivity. The solid biocatalyst is also shown to be stable both on stream and during storage. These essential features pave the way to the successful development of an environmentally friendly process for chiral amines production.
\end{abstract}

Keywords: chiral amines; biocatalysis; silica monolith; enzyme immobilization; flow chemistry

\section{Introduction}

While the use of enzymes as catalysts in the chemical sector is extremely appealing-especially in the perspective of sustainability-their application in industrially relevant processes is not straightforward. Indeed, the use of free enzymes in homogeneous batch processes suffers from severe limitations related to the impossibility to reuse and recover the biocatalysts [1]. Therefore, one particular challenge is to make them recyclable while maintaining their activity [2]. This is typically achieved by immobilizing the enzymes on an appropriate support-inorganic, biological, polymer or hybrid materials [3,4].

Of particular interest nowadays, is the use of $\omega$-transaminases for the greener production of chiral amines, which are chiral precursors of many important drugs [5-7]. Transaminases are enzymes that catalyze the enantioselective transfer of an amine group from an amine donor to an amino acceptor. Genetically, engineered transaminases have demonstrated excellent performance in the synthesis of important drug scaffolds [5]. In addition, keeping the recyclability issue in mind, researchers have proposed successful immobilization strategies for transaminases using for example natural and synthetic polymers [8-12] or silica [13-15] as carriers.

While enzymes immobilized on such powdery materials can be recovered by filtration or centrifugation after use in batch reactors, a second important challenge is to perform the enzymatic 
reaction in a continuous flow process. Indeed, the flow mode generally allows lowering the E-factor of a production process, by maintaining the catalyst active over large duration, by minimizing unproductive sequences and by reducing the waste/products ratio [16]. To design a truly green and industrially practicable process, the conversion of a batch process to a continuous flow process is often an essential step [17]. In the context of biocatalytic transamination, Andrade et al. demonstrated the flow production of chiral amines using immobilized mutants of $E$. coli-designed to overexpress the desired transaminase [18]. This elegant strategy, however, requires keeping the living organisms alive by feeding them with all the needed nutriments along the process.

Here, we propose the immobilization of a transaminase on silica monoliths that are particularly appropriate for the design of continuous flow reactors [19,20]. Si(HIPE) materials (where "HIPE" stands for "High Internal Phase Emulsion") were recently developed by an innovative sol-gel method based on emulsion templating [21]. They exhibit high void fraction that allows minimizing pressure drop. They are easier to manipulate as compared to powders because no further shaping, tableting or extrusion step is needed [22]. In addition, among the various supporting materials that can be used for enzyme immobilization, silica is particularly attractive because it is chemically inert, non-toxic and inexpensive. Moreover, its surface can be easily functionalized to allow the subsequent anchoring of enzymes [23]. For example, grafting amine groups on silica surface using (3-aminopropyl)triethoxysilane (APTES) favors electrostatic attraction between the silica carrier and the enzymes [24,25]. Furthermore, coupling agents such as glutaraldehyde can be used for the covalent cross-linking of enzymes through their lysine amino groups [26-29]. Thus, in this contribution, we make use of these structured Si(HIPE) supports and we implement several immobilization strategies to demonstrate the first example of a flow mode biocatalytic transamination process based on immobilized transaminases (Figure 1).

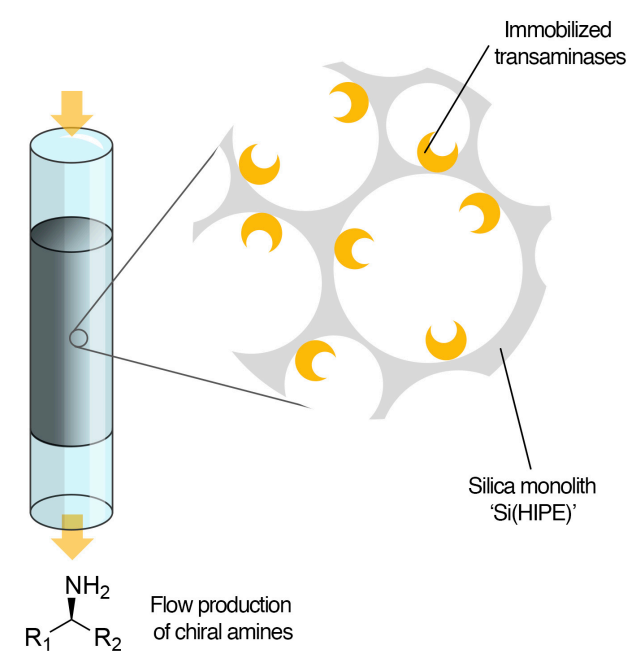

Figure 1. Transaminases have been immobilized on a macroporous silica monolith and used as biocatalyst for continuous flow transamination reaction.

\section{Results and Discussion}

\subsection{Enzyme Immobilization on Si(HIPE) Monoliths}

Synthesis of $\mathrm{Si}(\mathrm{HIPE})$ support is schematically described in the Supplementary Materials (Figure S1). Briefly, an emulsion is produced with a high proportion of dodecane as the dispersed phase and an acidic aqueous continuous phase containing tetraethyl orthosilicate. Hydrolysis and condensation reactions occur around oil droplets and lead to the formation of a macrocellular silica scaffold. After the removal of the oil phase, a self-standing monolith is obtained, featuring high specific surface area $\left(820 \mathrm{~m}^{2} \cdot \mathrm{g}^{-1}\right)$ and large void fraction $(\sim 95 \%)$. Further characterization is presented in Figure S2. 
The commercial $\omega$-transaminase (ATA-117 from Codexis) was immobilized on Si(HIPE) by three methods (Figure 2). In method (a), the enzyme solution $(0.2 \mathrm{~g} / \mathrm{L})$ was simply allowed to flow through the bare silica monolith and the enzyme was immobilized by simple physical adsorption. The monolith is then washed with the buffer solution (catalyst denoted "TA-Si(HIPE)", where TA stands for transaminase).

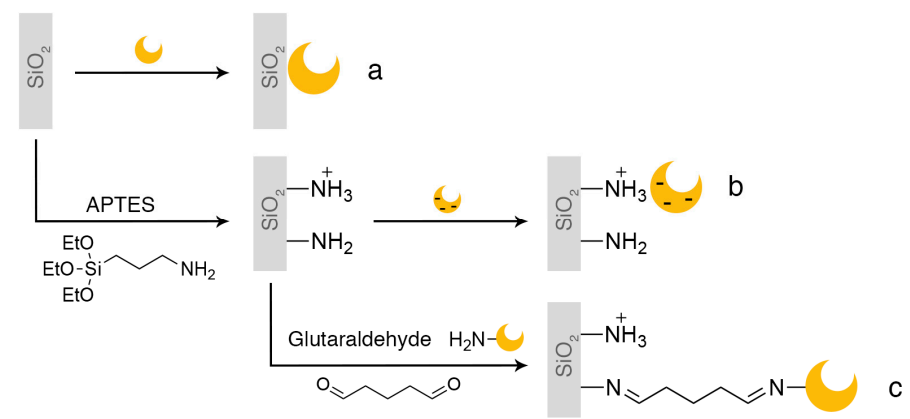

Figure 2. Immobilization methods: (a) simple adsorption; (b) adsorption assisted by electrostatic interactions; and (c) covalent grafting.

The external surface of ATA- 117 is negatively charged at the optimal working $\mathrm{pH}(\mathrm{pH}=8$; see Supplementary Materials, Figure S3). Thus, in method (b), the silica monolith was functionalized by APTES to bring amino functions that are positively charged at $\mathrm{pH}=8$; and the enzyme adsorption was assisted by electrostatic interactions. The initial amount of APTES introduced in the preparation of the support was varied and the catalysts are denoted "TA-Ax", where A stand for APTES and $\mathrm{x}$ is the APTES concentration used in the functionalization step.

ATA-117 external surface also exhibits six lysine residues (Figure S3). In method (c), glutaraldehyde was used as a coupling agent $[26,29]$ to promote the covalent grafting between the amino functions on the APTES-functionalized Si(HIPE) and the lysine residues of the enzyme (catalysts denoted "TA-A $x$-GA" where GA stand for glutaraldehyde).

The efficiency of APTES functionalization was verified by attenuated total reflectance infrared spectroscopy (ATR-FTIR). Signals related to the amino functions are difficult to identify: N-H vibration at $1610 \mathrm{~cm}^{-1}$ is overlapped by water band $\left(1600-1640 \mathrm{~cm}^{-1}\right)$ [30]; and C-N vibration at $2259 \mathrm{~cm}^{-1}$ is on a poor diamond crystal transmittance area [31]. However, an increase in intensity of absorbance band assigned to C-H stretching (from 2885 to $2974 \mathrm{~cm}^{-1}$ ) [30,32] is clearly observed when comparing the APTES-functionalized support with the pristine one (Figure 3). Expectedly, the intensity of this band increases with the APTES concentrations used for functionalization. Compared to the IR spectrum of pure APTES, the spectra of APTES-functionalized Si(HIPE) samples show a more intense band for $\mathrm{CH}_{2}$ vibrations ( 2855 and $2926 \mathrm{~cm}^{-1}$ ) and less intense band for $\mathrm{CH}_{3}$ stretching vibrations (2885 and $2974 \mathrm{~cm}^{-1}$ ) [30,32]. This indicates that ethoxy groups of APTES are eliminated during functionalization, consistent with the silanization process where ethoxy groups react with the silanol groups of the support.

Thermogravimetric analyses confirmed the presence of additional organic species in the APTES functionalized samples (Figure 4). A relatively well-defined weight loss is observed between 300 and $600{ }^{\circ} \mathrm{C}$ with the functionalized samples (and not with the pristine Si(HIPE)). It is thus assigned to aminopropyl moiety decomposition $[33,34]$. The weight loss is larger when the APTES concentration used to functionalize the silica monolith is higher.

In principle, the enzyme loading in each monolith can be evaluated by a simple mass balance between the solution used to load the monolith and the recovered solution, including the washing solution. Unfortunately, these measurements suffered from high variability and discrepancies, which prevent us from providing the precise enzyme loading for each monolith (as discussed in the Supplementary Materials, Figures S4 and S5). As a general trend, however, TA-Si(HIPE) and TA-Ax 
with low APTES content showed low enzyme loading values, certainly below $0.5 \mathrm{mg}$ of enzyme in the monolith. For the TA-Ax-GA catalysts with high APTES content, the loading is clearly higher and it is possible to provide an estimation of the enzyme loading. In TA-A50-GA-the most active catalyst, vide infra—enzyme loading was estimated at $1.2 \mathrm{mg}$.

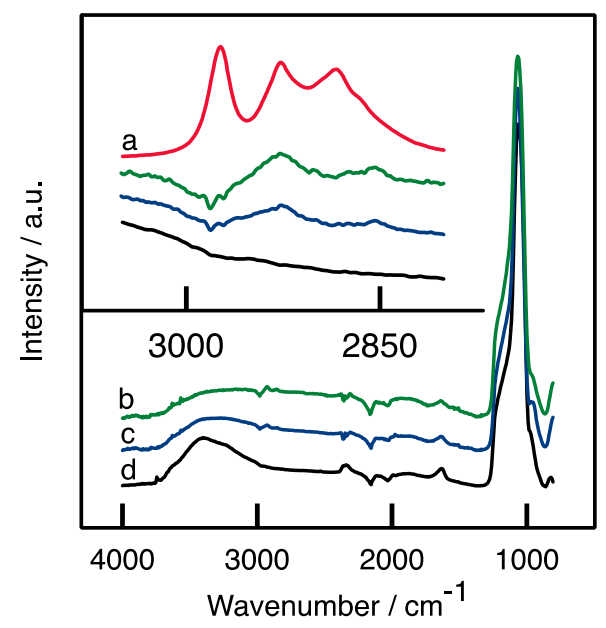

Figure 3. ATR-FTIR spectra of: (a) pure APTES ((3-aminopropyl)triethoxysilane); (b) TA-A50; (c) TA-A10; and (d) Si(HIPE). An increase in C-H stretching band absorbance (around $2900 \mathrm{~cm}^{-1}$ ) suggests a higher amount of aminopropyl groups grafted to monolith surface for higher APTES concentrations.

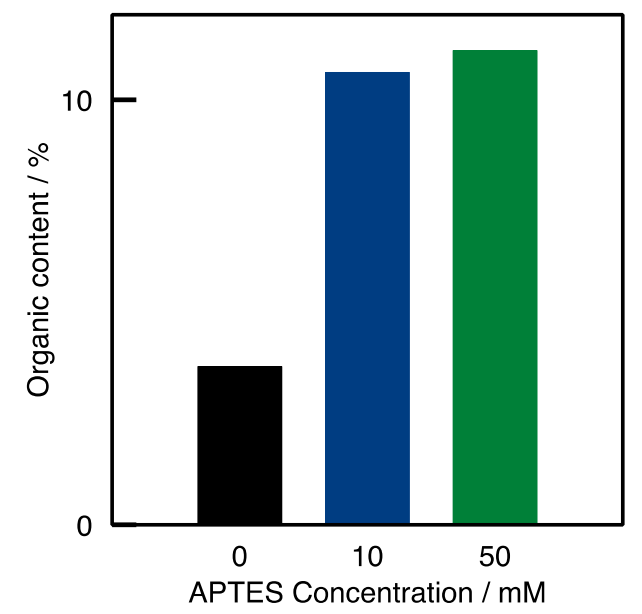

Figure 4. Relative organic content of Si(HIPE), TA-A10 and TA-A50 samples measured by TGA (relative mass loss over $150^{\circ} \mathrm{C}$ ).

\subsection{Transaminations in Continuous Flow Mode}

The kinetic resolution of racemic bromo- $\alpha$-methylbenzylamine (rac-BMBA) into 4 '-bromoacetophenone (BAP) was studied as a model transamination reaction to evaluate the performance of the solid biocatalysts (Figure 5). The thermodynamic equilibrium for this reaction is highly favorable and a conversion of $\sim 99 \%$ is expected at equilibrium $[35,36]$. However, without any catalyst, this conversion is very slow (see Supplementary Materials, Figure S6). In the presence of ATA-117, a $R$-selective transaminase, $R$-BMBA conversion into BAP is strongly catalyzed. In this paper, the yield is defined as the proportion of rac-BMBA converted to $4^{\prime}$-bromoacetophenone (BAP; in \%). The maximum yield for the kinetic resolution is thus $50 \%$. 


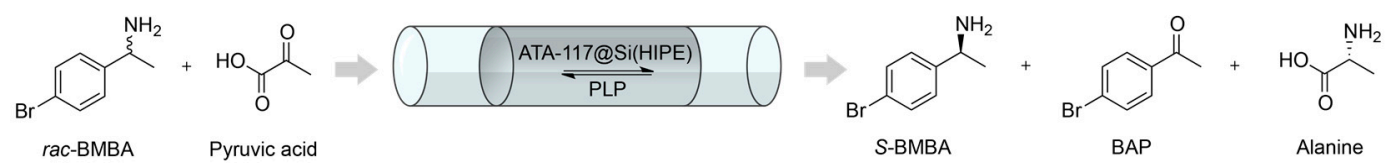

Figure 5. Flow kinetic resolution of rac-BMBA by ATA-117 transaminases immobilized on $\mathrm{Si}(\mathrm{HIPE})$ monolith. As ATA-117 is $R$-selective, it only accepts the $R$-BMBA as a substrate, leaving the $S$-BMBA unreacted. PLP stands for Pyridoxal phosphate, the transaminase cofactor.

The reaction is carried in flow mode in a homemade set-up in which the monolith is casted into a heat-shrinkable Teflon tube and connected to a syringe pump at one side and to a sample collector at the other side (Figure 6 and Figure S7). The set-up and the structure of the support prepared by the emulsion-based sol-gel method ensured a plug flow regime through the macroporous support (Figure S8). Relatively short contact times were selected to remain in the initial activity regime (low conversion).

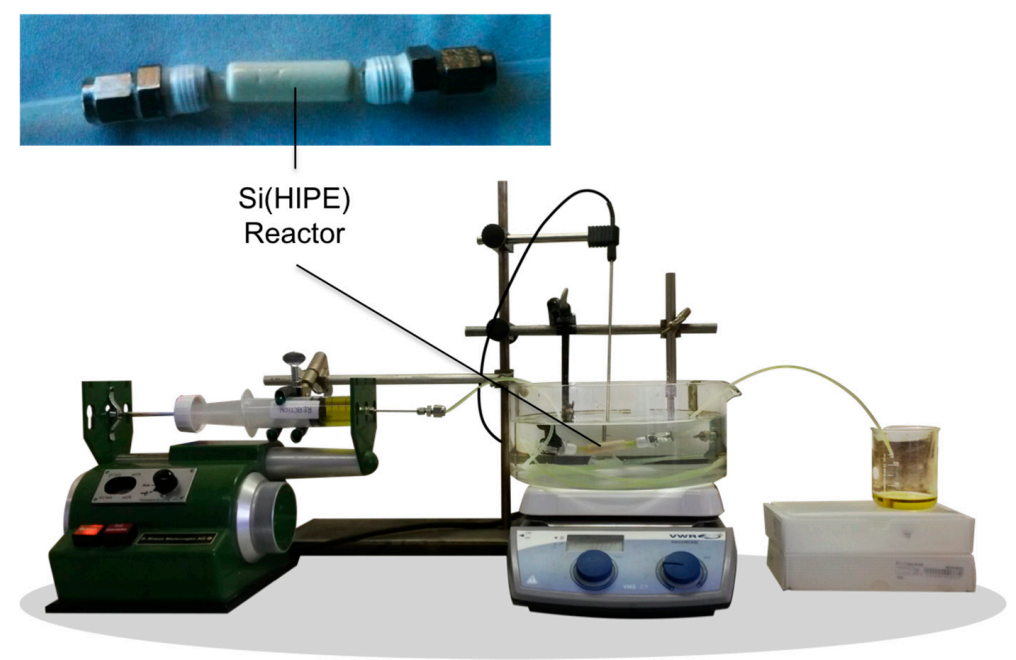

Figure 6. Si(HIPE) monolith placed in a heat-shrinkable PTFE tube. Monolithic reactor is connected to syringe-pump and immerged in a water bath.

The pristine $\mathrm{Si}(\mathrm{HIPE})$ and the APTES functionalized supports showed no catalytic activity (Figure S9). The pristine Si(HIPE) monolith was initially tested as a support for the transaminase (sample TA-Si(HIPE)). The yield was moderate, decreased in the first hour of reaction, and stabilized around $1.1 \%$ (Figure 7 ). Initial deactivation may tentatively be attributed to a partial leaching of the enzyme out of the monolith. Functionalization of the surface with APTES—as per method (b) - is expected to modify the surface charge of the silica support and to favor the electrostatic adsorption of the enzyme on the support. Indeed, higher conversion was obtained with TA-A10, but the activity level was not very stable with time. In method (c), a true covalent anchoring of the enzyme is obtained under the action of glutaraldehyde used as coupling agent between the amine functions incorporated on the surface of the support and the amine functions of the enzyme. Pre-activation with glutaraldehyde (TA-A10-GA) indeed allowed reaching directly a stable yield of $2.1 \%$.

In an attempt to further increase the reaction yield, the APTES concentration in the functionalization solution was raised to 20 and $50 \mathrm{mM}$, keeping all other parameters constant. The yield increased when the concentration of APTES used for functionalization increased (Figure 8), expectedly suggesting that a higher density of grafted APTES on the monolith surface is leading to a higher enzymatic loading. The highest BAP yield was obtained for TA-A50-GA sample (6.2\%). The experiment has been carried out three times and showed a good repeatability (relative standard deviation (RSD) was $9 \%)$. 


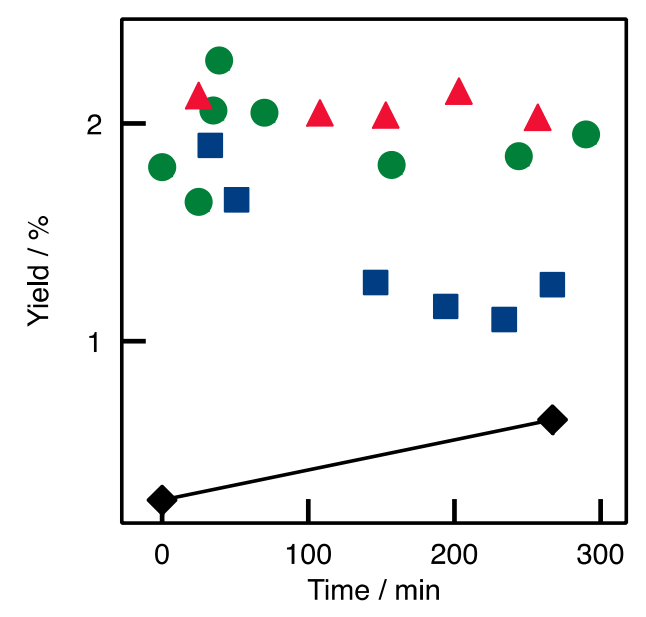

Figure 7. APTES and glutaraldehyde pre-activation effects on biocatalysts efficiency: (๘) Si(HIPE);

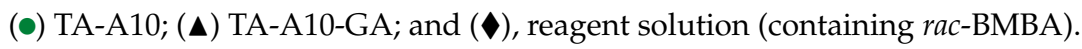

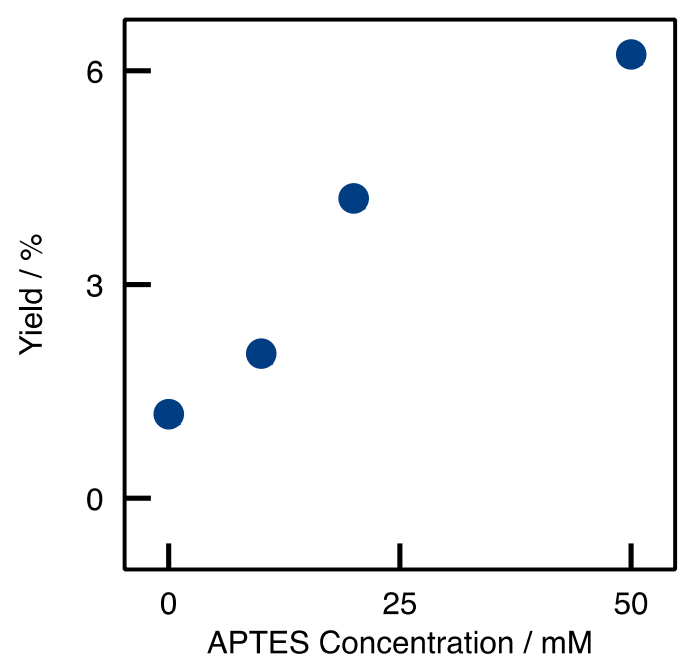

Figure 8. Effect of APTES concentration in the grafting solution on biocatalysts efficiency. Increasing APTES concentration allows enhancing the yield. Yield values are the averaged yield measured after $180 \mathrm{~min}$ time on stream (where the yield appeared to stabilize).

This level of conversion was achieved with a 10 min contact time. If the flow rate and the size of the monolith are varied in parallel while keeping the contact time constant, the yield remains at the same level (Figure S10). This confirms that the activity measurement is not biased by diffusional limitations. In addition, the level of conversion is far enough from the thermodynamic equilibrium to be considered as a measurement of the initial activity. Indeed, conversion is roughly divided by two or multiplied by two when the reaction is run with half a monolith or with tow monoliths, respectively (Figure S11).

Looking at the rough estimation of the enzyme loading in this monolith $(\sim 1.2 \mathrm{mg})$, it is possible to estimate the residual activity of the immobilized enzyme, as compared to the free enzyme. The conversion obtained in flow $(6.2 \%)$ is compared to the conversion of a homogeneous batch reactor containing the same amount of enzyme in the same conditions and after a period equal to the contact time. The ratio of the conversion in flow over the conversion in batch is the residual activity. The equivalent homogeneous batch should give a $37.5 \%$ yield in the same conditions, so that the residual activity is estimated to $16 \%$ in this case. 


\subsection{Applicability and Robustness of the Biocatalytic Flow Reactor}

A specific experiment was carried out to demonstrate that the enzyme remains enantioselective when immobilized (Figure 9). In the first part of the experiment, only S-BMBA was fed in the reactor (instead of the racemic BMBA). As expected, the BAP yield remain very low at the reactor flow output, corresponding exactly to the non-catalytic conversion occurring in the reagent solution in the sole presence of PLP. After $180 \mathrm{~min}$, the racemic BMBA solution was injected in the reactor. After a 140-min lag time required time for the reaction medium to pass through the flow device, BAP yield reaches $6 \%$ again. This demonstrates unambiguously that ATA-117 immobilized in the flow reactor remains enantioselective.

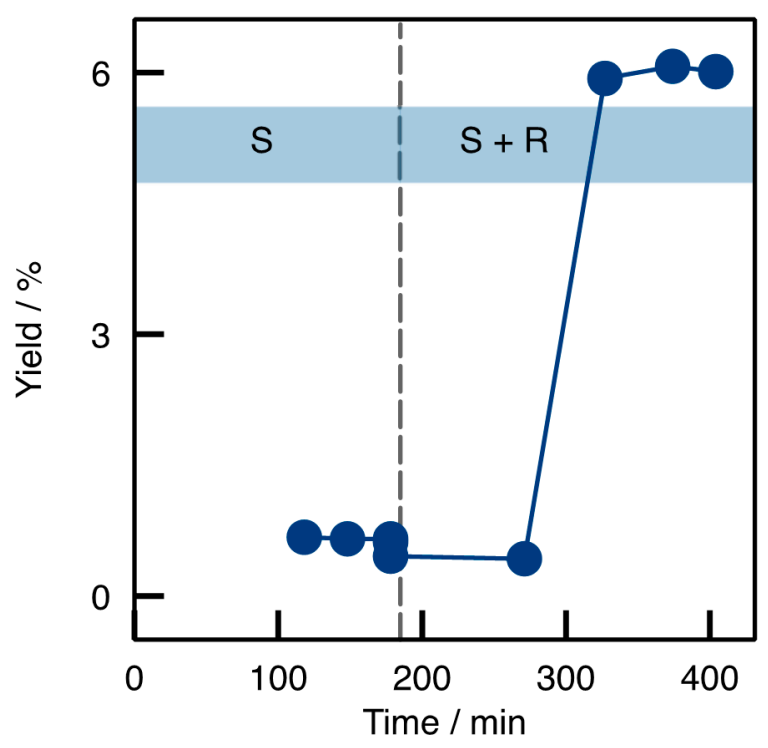

Figure 9. TA-A50-GA enantioselectivity. With S-BMBA enantiomer, the yield is low and corresponds to the non-enzymatic reaction. When the racemic BMBA is injected in the reactor at $180 \mathrm{~min}$, the yield raises up to $6 \%$ after $2 \mathrm{~h}$, which is the time required for the solution to reach the output.

From an industrial perspective, it is important to ensure that the biocatalyst allows reaching total conversion, i.e., the actual kinetic resolution with only one BMBA enantiomer remaining at the output. To that end, eight functionalized monoliths were connected in series and then pre-activated with glutaraldehyde and loaded with the enzyme (TA-A50-GA samples, Figure 10). After a 200-min lag time required time for the reaction medium to pass fully through the flow device, the yield reached the maximum of $50 \%$. R-BMBA was fully converted, as attested by chiral HPLC.

To assess storage stability and recyclability, a TA-A50-GA biocatalyst was tested in a classical flow reaction, which was interrupted after $4 \mathrm{~h}$. The reactor was sealed at both ends and stored at $4{ }^{\circ} \mathrm{C}$ for $16 \mathrm{~h}$. Then, the reactor was again put in place in the flow set-up and fresh reaction medium was fed. The yield was practically as high as before cold storage ( $~ 5.5 \%$ instead of $\sim 6 \%$; Figure 11$)$. After $5 \mathrm{~h}$ of reaction, the reactor was again removed, sealed and stored at $4{ }^{\circ} \mathrm{C}$ for $68 \mathrm{~h}$. Then, it was tested again with fresh reaction medium and the final yield was still $\sim 4.7 \%$. Thus, residual activity was $80 \%$ after four days of cold storage, which indicates a good stability and recyclability of the biocatalysts. 


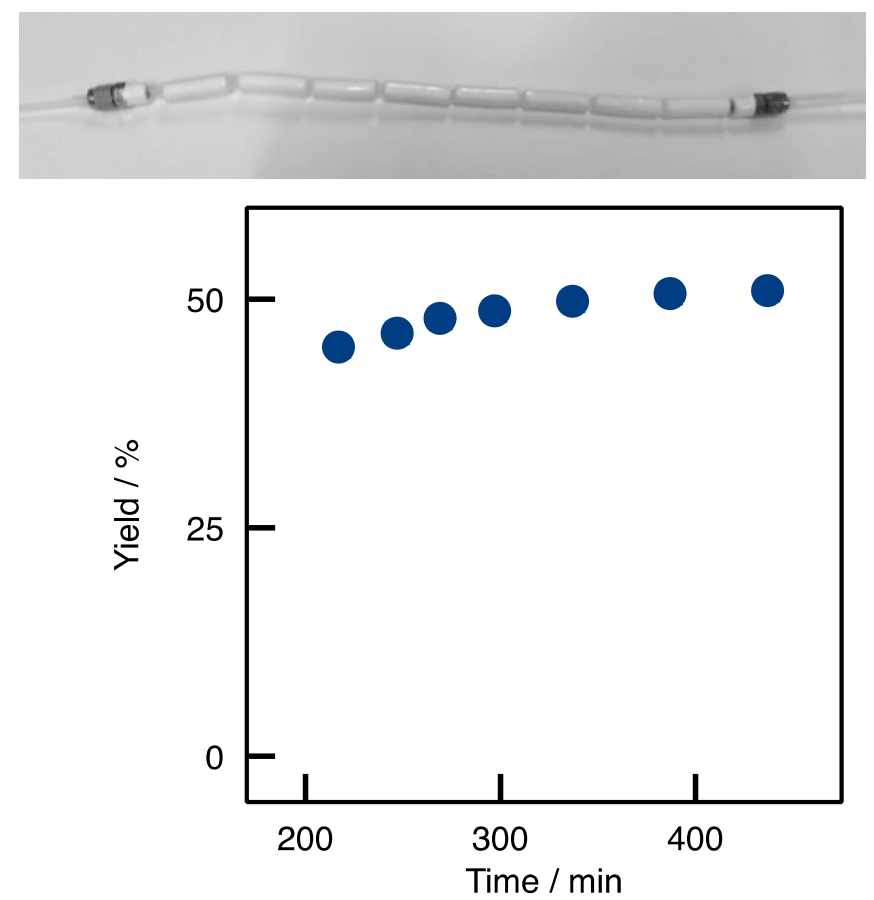

Figure 10. (Top) Reactor made of eight TA-A50-GA samples in series in order to reach total conversion. (Bottom) Total conversion is reached by increasing contact time (eight TA-A50-GA samples in series).

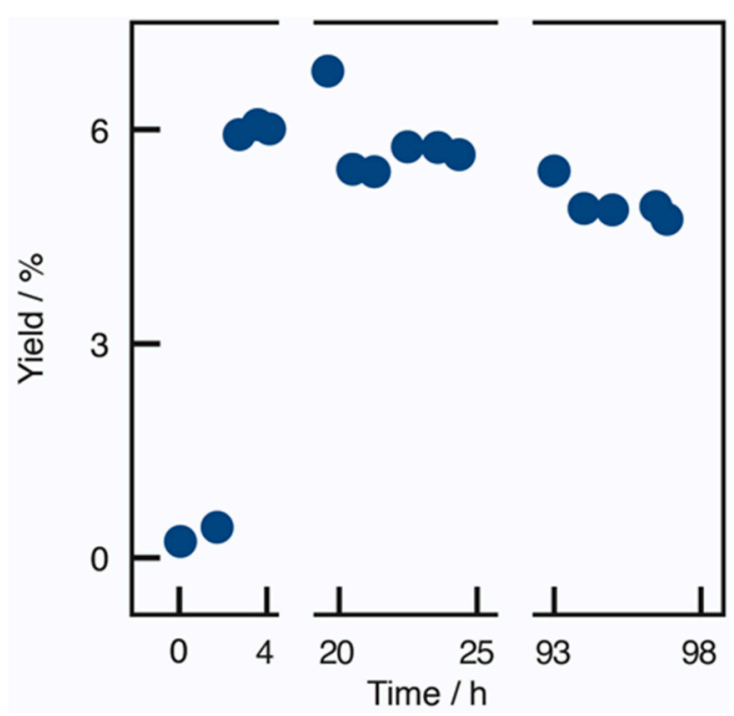

Figure 11. Yield with TA-A50-GA, flow reaction is carried out for periods of $\sim 14 \mathrm{~h}$ interrupted by cold storage.

\section{Materials and Methods}

\subsection{Materials}

Acetone ( $\geq 99.9 \%)$, (3-aminopropyl)triethoxysilane (APTES; $\geq 98 \%$ ), Brilliant blue G 250, 4'-bromoacetophenone (BAP; $\geq 98 \%$ ), $R$-4-bromo- $\alpha$-methylbenzylamine ( $R$-BMBA, $99 \%$ ), S-4-bromo- $\alpha$ methylbenzylamine (S-BMBA, $99 \%)$, dodecane ( $\geq 90 \%)$, hydrochloric acid ( $37 \% \mathrm{wt}$, aqueous solution), phosphoric acid aqueous solution (85\%), pyridoxal 5'-phosphate hydrate (PLP; $\geq 98 \%$ ), sodium hydroxide aqueous solution ( $50 \%$ ), sodium pyruvate ( $\geq 99 \%$ ), tetraethyl orthosilicate (TEOS; $\geq 98 \%$ ), toluene ( $\geq 99.8 \%$, anhydrous) and trimethyltetradecylammonium bromide (TTAB; $\geq 99 \%$ ) were 
purchased from Sigma-Aldrich (Darmstadt, Germany). 4-bromo- $\alpha$-methylbenzylamine (rac-BMBA; $\geq 99 \%$; racemate), dibasic potassium phosphate ( $\geq 99 \%$ ), dimethylsulfoxide (DMSO; $\geq 99.8 \%$ ) and monobasic potassium phosphate $(\geq 99 \%)$ were purchased from Acros (Geel, Belgium). Dichloromethane ( $\geq 99.80 \%$ ), diethylamine ( $\geq 99 \%$ ), isohexane (HPLC grade), 2-propanol (HPLC grade) and tetrahydrofuran (THF; $\geq 99.6 \%$ ) were purchased from VWR (Leuven, Belgium). Heat-shrinkable polytetrafluoroethylene (PTFE) tube was purchased from RS Components (Brussels, Belgium). Transaminase ATA-117 was generously supplied by Codexis (Redwood, CA, USA). Distilled water was applied for all synthesis and treatment processes.

\subsection{Support Synthesis—Si(HIPE) Monolith}

Porous monoliths synthesis was performed according to Ungureanu et al. [21] (see Supplementary Materials, Figure S1): $6 \mathrm{~g}$ of a concentrated hydrochloric acid solution ( $37 \% \mathrm{wt})$ were introduced in $16 \mathrm{~g}$ of a TTAB aqueous solution ( $35 \% \mathrm{wt}$ ). Then $5 \mathrm{~g}$ of TEOS was added. The aqueous phase was stirred until a monophasic hydrophilic medium was obtained. To form an emulsion, $35 \mathrm{~g}$ dodecane was then added dropwise in a mortar while stirring. Emulsion was cast into a polypropylene $10 \mathrm{~mL}$ flask, allowed to condense for 1 week at room temperature. Resulting material was washed three times with $50 \mathrm{~mL}$ of a THF/acetone mixture $(1: 1 \mathrm{v} / \mathrm{v})$ (each washing lasted $24 \mathrm{~h}$ ) and then gently dried in air during 3 days before calcined at $650{ }^{\circ} \mathrm{C}$ for $6 \mathrm{~h}$ (heating rate of $2{ }^{\circ} \mathrm{C} / \mathrm{min}$ with a first plateau at $180^{\circ} \mathrm{C}$ for $6 \mathrm{~h}$ ). Porous monoliths were stored in a desiccator at room temperature.

\subsection{Functionalization of the Monolith Surface}

Samples are denoted Ax where A stands for APTES grafting and $x$ is the concentration in APTES (mM) in the grafting solution. This protocol was adapted from Ungureanu et al. [21]: 2 monoliths (approximately $0.15 \mathrm{~g}$ each) were added into $25 \mathrm{~mL}$ of a toluene/APTES solution of desired concentration. Dynamic vacuum was applied to force the solution into the pores of the monoliths, until effervescence stopped. Static vacuum was then maintained for $24 \mathrm{~h}$. Monoliths were separated from the toluene/APTES solution and washed three times with $25 \mathrm{~mL}$ of a toluene/acetone mixture $(1: 1 v / v)$ by applying dynamic vacuum until effervescence stopped and static vacuum for $2 \mathrm{~h}$. Hybrid monoliths were dried under vacuum at $60^{\circ} \mathrm{C}$ for $24 \mathrm{~h}$ and then stored in a desiccator at room temperature.

\subsection{Characterizations}

\subsubsection{Attenuated Total Reflectance-InfraRed spectroscopy (ATR-FTIR)}

Samples were analyzed using a Bruker Equinox 55 (Bruker, Brussels, Belgium) with a Platinum ATR cell, with a diamond crystal, and Trans DTGS detector. One hundred scans were taken for both background and samples, with a resolution of $2 \mathrm{~cm}^{-1}$. ATR correction was applied (number of ATR reflection is 1; angle of incidence is $45^{\circ}$; mean reflection index of sample is 1.5). Monoliths were systematically crushed.

\subsubsection{Thermo Gravimetric Analysis (TGA)}

Samples were dried under vacuum at $105^{\circ} \mathrm{C}$ for $24 \mathrm{~h}$. TGA was performed under air flow $(100 \mathrm{~mL} / \mathrm{min})$ with heating rate of $10{ }^{\circ} \mathrm{C} / \mathrm{min}$ from $25^{\circ} \mathrm{C}$ until $900{ }^{\circ} \mathrm{C}$ with a TGA/SDTA-851e Mettler Toledo equipment (Mettler Toledo, Zaventem, Belgium).

\subsubsection{Scanning Electron Microscopy (SEM)}

SEM micrographs were taken with a JEOL 7600F (JEOL, Zaventem, Belgium) operated at a $15.0 \mathrm{kV}$ voltage. Samples were dried under vacuum at $60^{\circ} \mathrm{C}$ for $24 \mathrm{~h}$ and then placed on a piece of carbon black tape on an aluminium stub. A chromium sputter coating of $10 \mathrm{~nm}$ was carried out under vacuum with a Cressington Sputter Metal 208 HR (Cressington, Watford, UK). 


\subsubsection{Nitrogen Physisorption}

Adsorption-desorption isotherms of nitrogen were determined at $77 \mathrm{~K}$ using a Micromeritics Tristar 3000 instrument (Micromeritics, Brussels, Belgium). Samples were degassed at $120{ }^{\circ} \mathrm{C}$ under dynamic vacuum for $24 \mathrm{~h}$ prior to textural measurements. Specific surface area were determined by the Brunauer-Emmet-Teller Method (BET).

\subsection{Transamination Activity Determination}

A model reaction was used to assess catalytic activity of ATA-117: the transamination of pyruvate with racemic BMBA, to produce $\mathrm{BAP}$ and D-alanine. As the enzyme only accepts $R$-BMBA as a substrate, this reaction is a kinetic resolution. Typical conditions were $30^{\circ} \mathrm{C}$, phosphate buffer $0.1 \mathrm{M}$ pH 8, pyridoxal phosphate $2.02 \mathrm{mM}$, sodium pyruvate $10 \mathrm{mM}$, racemic BMBA $10 \mathrm{mM}$, DMSO 5\%. Batch reactions were carried out in triplicates (plus a blank) in $5 \mathrm{~mL}$ round bottom glass flasks under moderate magnetic stirring.

Transamination reaction conversion was determined on $100 \mu \mathrm{L}$ sample taken from the reaction medium. Ten microliters of sodium hydroxide $(2 \mathrm{M})$ was added and the mixture was vortexed for $1 \mathrm{~s}$. Five hundred microliters of dichloromethane was then added to the aqueous phase and vortexed for $10 \mathrm{~s}$ to allow extraction of BAP and BMBA into the organic phase. Extraction step was repeated twice and the organic phase was collected and analyzed by gas chromatography (analysis performed on a Bruker Scion 456-GC with a WCOT fused silica BR-5 column $(30 \mathrm{~m} \times 0.32 \mathrm{~mm}$ ID $\times 1.0 \mu \mathrm{m})$ and helium as carrier gas $(25 \mathrm{~mL} / \mathrm{min})$, oven temperature at $150{ }^{\circ} \mathrm{C}$, split ratio of 20 , injector temperature at $250{ }^{\circ} \mathrm{C}$, flame ionization detector temperature at $300{ }^{\circ} \mathrm{C}$ (air flow $300 \mathrm{~mL} / \mathrm{min}, \mathrm{H}_{2}$ flow $30 \mathrm{~mL} / \mathrm{min}$ ) (Bruker MicroCT, Kontich, Belgium). BAP yield is defined as the proportion of rac-BMBA converted to $\mathrm{BAP}$ (in \%).

\subsection{Enantiomeric Excess Determination}

Enantiomeric excess of bromo- $\alpha$-methylbenzylamine was determined by normal phase high performance liquid chromatography (HPLC) (Hitachi-koki, Chiyoda, Japan) at $252 \mathrm{~nm}$ using a Merck-Hitachi LaChrom L-7000 HPLC and a Chiralpak AD-H (250 mm $\times 4.6 \mathrm{~mm})$ column with a flow rate of $1 \mathrm{~mL} / \mathrm{min}$ (90\% isohexane/10\% 2-propanol/0.1\% diethylamine) for $10 \mathrm{~min}$. The retention times of the $S$ - and $R$-enantiomers were 4.32 and $5.42 \mathrm{~min}$, respectively. Specific rotation of the BMBA product was established by comparison to known standards.

\subsection{Enzyme Quantitation}

Enzymatic concentrations were assessed by a modified Bradford method [37,38], using the Bovine Serum Albumin protein as a standard. Five hundred microliters of sample were added to $1500 \mu \mathrm{L}$ of Bradford reagent. After $10 \mathrm{~min}$ incubation at room temperature, absorbances were read at 595 and $470 \mathrm{~nm}$ with a spectrophotometer ThermoScientific Genesys 10S-Vis (Thermo Fisher Scientific Inc., Waltham, MA, USA).

\subsection{Dynamic Light Scattering (DLS)}

DLS experiments were performed on a Malvern CGS-3 apparatus (Malvern Instruments, Hoeilaart, Belgium) equipped with a He-Ne laser with a wavelength of $633 \mathrm{~nm}$. The measurements were performed at a $90^{\circ}$ angle. Solutions were analyzed without any treatment. Five measurements were taken for each sample (analysis duration was $30 \mathrm{~s}$ for each measurement). The data were analyzed using the constrained regularization method for inverting data method, based on inverse-Laplace transformation of the data. 


\subsection{Flow Reactions}

\subsubsection{Flow Reactor}

A monolith was inserted into a heat-shrinkable PTFE tube, which perfectly fits the monolith shape when heated preventing preferential flows along monolith sides. Heat-shrinkable PTFE tube was also shrunk around Swagelok stainless steel male connectors (surrounded by PTFE tape to ensure sealing), themselves connected to PTFE pipes. Flow device was connected to a PP Terumo syringe. Syringe-pumps were used to deliver a controlled liquid flow. Monolithic reactors were placed in a thermo-regulated water bath.

\subsubsection{Transaminases Immobilization}

Each reactor was impregnated with $50 \mathrm{~mL}$ of $0.2 \mathrm{~g} / \mathrm{L}$ enzyme solution in buffer (potassium phosphate buffer $0.1 \mathrm{M} \mathrm{pH} 8$, pyridoxal phosphate $2.02 \mathrm{mM}$, sodium pyruvate $10 \mathrm{mM}$ ) with a flow rate of $1.4 \mathrm{~mL} / \mathrm{min}$, with the water bath maintained at $6{ }^{\circ} \mathrm{C}$ with ice packs. The effect of the enzyme concentration for loading the monolith was investigated and $0.2 \mathrm{~g} / \mathrm{L}$ was found to be sufficient to reach maximal loading (Figure S10). Then, the reactor was washed at room temperature with $50 \mathrm{~mL}$ buffer, with a flow rate of $1.4 \mathrm{~mL} / \mathrm{min}$, until no enzyme is detected in the outflow. Practically, this was achieved after using approximately $30 \mathrm{~mL}$ of buffer solution. In some cases (covalent grafting), $50 \mathrm{~mL}$ of a $1 \%$ glutaraldehyde aqueous solution was passed through the reactor (flow rate of $1.4 \mathrm{~mL} / \mathrm{min}$ ) at room temperature before enzyme impregnation.

\subsubsection{Flow Transamination Reaction}

The model reaction was used to assess catalytic activity of ATA-117. Reaction medium (same conditions as in batch reactions) was loaded in syringe and injected into the reactor with a flow rate of $0.11 \mathrm{~mL} / \mathrm{min}$. Catalytic activity was determined by collecting the outflows and measuring BMBA consumption and BAP production in gas chromatography. During enzymatic reaction, actual flow rates were continuously monitored allowing an accurate determination of contact time. Porous volume was estimated by weighing monolith before and after reaction (reaction medium density was measured at 1.0024).

\section{Conclusions}

For the first time, $\omega$-transaminases have been successfully immobilized on porous silica monoliths and used in flow transamination reaction. When covalently grafted on APTES-functionalized silica monoliths, using glutaraldehyde as a coupling agent, the enzyme shows good activity and full enantioselectivity allowing the total kinetic resolution of racemic amines mixture. Biocatalysts were stable both over time and upon storage. This study shows that such heterogeneous biocatalyst exhibits all the required features for an enzymatic flow process. It paves the way to the development of industrially relevant processes in continuous flow mode, based on heterogeneous biocatalysis, and in particular the greener production of chiral amines.

Supplementary Materials: The following are available online at www.mdpi.com/2073-4344/7/2/54/s1, Figure S1: $\mathrm{Si}(\mathrm{HIPE})$ monolith synthesis, Figure S2: Si(HIPE) monolith texture and SEM micrograph, Figure S3: ATA-117 Protein sequence and surface properties, Figure S4: Loading estimation for TA-A50-GA samples, Figure S5: Dynamic light scattering analysis of ATA-117 solutions, Figure S6: Kinetic resolution in batch mode (yield and enantioselectivity), Figure S7: Flow reactor manufacture with heat-shrinkable membrane, Figure S8: Plug flow regime into Si(HIPE) monolith, Figure S9: Non-enzymatic reactions (batch and flow), Figure S10: Activity dependence on flow rate, Figure S11: Activity dependence on contact time.

Acknowledgments: The financial support of the Fond Spécial de Recherche from Université catholique de Louvain is gratefully acknowledged. Authors also acknowledge the Communauté française de Belgique for the financial support-including the PhD fellowship of L. van den Biggelaar-through the ARC programme (15/20-069).

Author Contributions: L.v.d.B. performed the experiments, analyzed the data and wrote the paper. P.S. and D.P.D. conceived and designed the experiments, analyzed the data and wrote the paper. 
Conflicts of Interest: The authors declare no conflict of interest.

\section{References}

1. Bornscheuer, U.T. Immobilizing enzymes: How to create more suitable biocatalysts. Angew. Chem. Int. Ed. 2003, 42, 3336-3337. [CrossRef] [PubMed]

2. Singh, R.K.; Tiwari, M.K.; Singh, R.; Lee, J.K. From protein engineering to immobilization: Promising strategies for the upgrade of industrial enzymes. Int. J. Mol. Sci. 2013, 14, 1232-1277. [CrossRef]

3. Sheldon, R.A.; van Pelt, S. Enzyme immobilisation in biocatalysis: Why, what and how. Chem. Soc. Rev. 2013, 42, 6223-6235. [CrossRef] [PubMed]

4. Cao, L. Carrier-Bound Immobilized Enzymes; John Wiley \& Sons: Hoboken, NJ, USA, 2006.

5. Savile, C.K.; Janey, J.M.; Mundorff, E.C.; Moore, J.C.; Tam, S.; Jarvis, W.R.; Colbeck, J.C.; Krebber, A.; Fleitz, F.J.; Brands, J.; et al. Biocatalytic asymmetric synthesis of chiral amines from ketones applied to sitagliptin manufacture. Science 2010, 329, 305-309. [CrossRef] [PubMed]

6. Sehl, T.; Hailes, H.C.; Ward, J.M.; Wardenga, R.; von Lieres, E.; Offermann, H.; Westphal, R.; Pohl, M.; Rother, D. Two steps in one pot: Enzyme cascade for the synthesis of nor(pseudo)ephedrine from inexpensive starting materials. Angew. Chem. Int. Ed. 2013, 52, 6772-6775. [CrossRef] [PubMed]

7. Girardin, M.; Ouellet, S.G.; Gauvreau, D.; Moore, J.C.; Hughes, G.; Devine, P.N.; O’Shea, P.D.; Campeau, L.C. Convergent kilogram-scale synthesis of dual orexin receptor antagonist. Org. Process Res. Dev. 2012, 17, 61-68. [CrossRef]

8. Cárdenas-Fernández, M.; Khalikova, E.; Korpela, T.; López, C.; Álvaro, G. Co-immobilised aspartase and transaminase for high-yield synthesis of L-phenylalanine. Biochem. Eng. J. 2015, 93, 173-178. [CrossRef]

9. Yi, S.S.; Lee, C.W.; Kim, J.; Kyung, D.; Kim, B.G.; Lee, Y.S. Covalent immobilization of $\omega$-transaminase from Vibrio fluvialis JS17 on chitosan beads. Process Biochem. 2007, 42, 895-898. [CrossRef]

10. Truppo, M.D.; Strotman, H.; Hughes, G. Development of an Immobilized Transaminase Capable of Operating in Organic Solvent. Chem CatChem 2012, 4, 1071-1074. [CrossRef]

11. Mallin, H.; Menyes, U.; Vorhaben, T.; Höhne, M.; Bornscheuer, U.T. Immobilization of two (R)-Amine Transaminases on an Optimized Chitosan Support for the Enzymatic Synthesis of Optically Pure Amines. ChemCatChem 2013, 5, 588-593. [CrossRef]

12. Mallin, H.; Höhne, M.; Bornscheuer, U.T. Immobilization of (R)- and (S)-amine transaminases on chitosan support and their application for amine synthesis using isopropylamine as donor. J. Biotechnol. 2014, 191, 32-37. [CrossRef] [PubMed]

13. Lee, J.; Kim, J.; Hyeon, T. Recent progress in the synthesis of porous carbon materials. Adv. Mater. 2006, 18, 2073-2094. [CrossRef]

14. Koszelewski, D.; Müller, N.; Schrittwieser, J.H.; Faber, K.; Kroutil, W. Immobilization of $\omega$-transaminases by encapsulation in a sol-gel/celite matrix. J. Mol. Catal. B Enzym. 2010, 63, 39-44. [CrossRef]

15. Yang, L.; Shi, J.; Chen, C.; Wang, S.; Zhu, L.; Xie, W.; Guo, L. Dual-enzyme, co-immobilized capillary microreactor combined with substrate recycling for high-sensitive glutamate determination based on CE. Electrophoresis 2009, 30, 3527-3533. [CrossRef] [PubMed]

16. Sheldon, R.A. The E Factor: Fifteen years on. Green Chem. 2007, 9, 1273-1283. [CrossRef]

17. Jas, G.; Kirschning, A. Continuous Flow Techniques in Organic Synthesis. Chem. Eur. J. 2003, 9, 5708-5723. [CrossRef] [PubMed]

18. Andrade, L.H.; Kroutil, W.; Jamison, T.F. Continuous Flow Synthesis of Chiral Amines in Organic Solvents: Immobilization of E. coli Cells Containing Both $\omega$-Transaminase and PLP. Org. Lett. 2014, 16, 6092-6095.

19. Debecker, D.P.; Boissière, C.; Laurent, G.; Huet, S.; Eliaers, P.; Sanchez, C.; Backov, R. First acidic macro-mesocellular aluminosilicate monolithic foams "SiAl(HIPE)" and their catalytic properties. Chem. Commun. 2015, 51, 14018-14021. [CrossRef] [PubMed]

20. Brun, N.; Babeau-Garcia, A.; Achard, M.-F.; Sanchez, C.; Durand, F.; Laurent, G.; Birot, M.; Deleuze, H.; Backov, R. Enzyme-based biohybrid foams designed for continuous flow heterogeneous catalysis and biodiesel production. Energy Environ. Sci. 2011, 4, 2840-2844. [CrossRef]

21. Ungureanu, S.; Laurent, G.; Deleuze, H.; Babot, O.; Achard, M.-F.; Popa, M.I.; Sanchez, C.; Backov, R. Syntheses and characterization of new organically grafted silica foams. Colloids Surfaces A 2010, 360, 85-93. [CrossRef] 
22. Kirschning, A.; Solodenko, W.; Mennecke, K. Combining enabling techniques in organic synthesis: Continuous flow processes with heterogenized catalysts. Chem. Eur. J. 2006, 12, 5972-5990. [CrossRef] [PubMed]

23. Nandiyanto, A.B.D.; Kim, S.G.; Iskandar, F.; Okuyama, K. Synthesis of spherical mesoporous silica nanoparticles with nanometer-size controllable pores and outer diameters. Microporous Mesoporous Mater. 2009, 120, 447-453. [CrossRef]

24. Lazghab, M.; Saleh, K.; Guigon, P. Functionalisation of porous silica powders in a fluidised-bed reactor with glycidoxypropyltrimethoxysilane (GPTMS) and aminopropyltriethoxysilane (APTES). Chem. Eng. Res. Des. 2010, 88, 686-692. [CrossRef]

25. Gaffney, D.; Cooney, J.; Magner, E. Modification of mesoporous silicates for immobilization of enzymes. Top. Catal. 2012, 55, 1101-1106. [CrossRef]

26. Bai, Y.-X.; Li, Y.-F.; Yang, Y.; Yi, L.-X. Covalent immobilization of triacylglycerol lipase onto functionalized novel mesoporous silica supports. Process Biochem. 2006, 41, 770-777. [CrossRef]

27. Brun, N.; Babeau Garcia, A.; Deleuze, H.; Achard, M.F.; Sanchez, C.; Durand, F.; Oestreicher, V.; Backov, R. Enzyme-based hybrid macroporous foams as highly efficient biocatalysts obtained through integrative chemistry. Chem. Mater. 2010, 22, 4555-4562. [CrossRef]

28. Zaidan, U.H.; Rahman, M.B.A.; Basri, M.; Othman, S.S.; Rahman, R.N.Z.R.A.; Salleh, A.B. Silylation of mica for lipase immobilization as biocatalysts in esterification. Appl. Clay Sci. 2010, 47, 276-282. [CrossRef]

29. Tran, D.N.; Balkus, K.J. Perspective of recent progress in immobilization of enzymes. ACS Catal. 2011, 1, 956-968. [CrossRef]

30. Pasternack, R.M.; Amy, S.R.; Chabal, Y.J. Attachment of 3-(Aminopropyl) triethoxysilane on Silicon Oxide Surfaces: Dependence on Solution Temperature. Langmuir 2008, 24, 12963-12971. [CrossRef] [PubMed]

31. Putz, A.M.; Putz, M.V. Spectral inverse quantum (Spectral-IQ) method for modeling mesoporous systems: Application on Silica films by FTIR. Int. J. Mol. Sci. 2012, 13, 15925-15941. [CrossRef] [PubMed]

32. Etienne, M.; Walcarius, A. Analytical investigation of the chemical reactivity and stability of aminopropyl-grafted silica in aqueous medium. Talanta 2003, 59, 1173-1188. [CrossRef]

33. Kursunlu, A.N.; Guler, E.; Dumrul, H.; Kocyigit, O.; Gubbuk, I.H. Chemical modification of silica gel with synthesized new Schiff base derivatives and sorption studies of cobalt (II) and nickel (II). Appl. Surf. Sci. 2009, 255, 8798-8803. [CrossRef]

34. Hu, Z.; Xu, L.; Wen, X. Mesoporous silicas synthesis and application for lignin peroxidase immobilization by covalent binding method. J. Environ. Sci. 2012, 25, 181-187. [CrossRef]

35. Tufvesson, P.; Jensen, J.S.; Kroutil, W.; Woodley, J.M. Experimental determination of thermodynamic equilibrium in biocatalytic transamination. Biotechnol. Bioeng. 2012, 109, 2159-2162. [CrossRef] [PubMed]

36. Tufvesson, P.; Bach, C.; Woodley, J.M. A model to assess the feasibility of shifting reaction equilibrium by acetone removal in the transamination of ketones using 2-propylamine. Biotechnol. Bioeng. 2014, 111, 309-319. [CrossRef] [PubMed]

37. Bradford, M.M. A rapid and sensitive method for the quantitation of microgram quantities of protein utilizing the principle of protein-dye binding. Anal. Biochem. 1976, 72, 248-254. [CrossRef]

38. Zor, T.; Selinger, Z. Linearization of the Bradford Protein Assay Increases Its Sensitivity: Theoretical and Experimental Studies. Anal. Biochem. 1996, 236, 302-308. [CrossRef] [PubMed]

(C) 2017 by the authors; licensee MDPI, Basel, Switzerland. This article is an open access article distributed under the terms and conditions of the Creative Commons Attribution (CC BY) license (http://creativecommons.org/licenses/by/4.0/). 